\title{
Human Parainfluenza Type 1 Antigen Measurement
}

National Cancer Institute

\section{Source}

National Cancer Institute. Human Parainfluenza Type 1 Antigen Measurement. NCI

Thesaurus. Code C154834.

The determination of the human parainfluenza type 1 antigen present in a sample. 